\title{
Flurförderzeuge
}

\section{in Zeiten Industrie 4.0}

Liebe Leserin, lieber Leser,

auch in der Logistikbranche findet Industrie 4.0 zunehmend Widerhall in Produkten und Lösungen. Die raschen Entwicklungszyklen etwa in der Sensorik oder Bilderfassung ermöglichen dabei völlig neue Automatisierungslösungen. So müssen Flurförderzeuge heute nicht nur mit dem Menschen kommunizieren können, sondern auch mit anderen Maschinen und Fahrzeugen. Des Weiteren müssen sie mit den ERP-Systemen des Betreibers sowie idealerweise auch mit dem Fahrzeughersteller selbst vernetzt sein. Dies alles soll letztendlich der Steigerung der Effizienz dienen.

Wie solche Industrie-4.0-Lösungen aussehen können, präsentierte Still auf der LogiMat, die Anfang März dieses Jahres stattfand. Mit dem Kommissionierfahrzeug iGo neo CX20 führt das Hamburger Unternehmen als erster Flurförderzeughersteller die mobile Robotik serienmäßig in die Intralogistik ein, so der Geschäftsführer von Still, Thomas Fischer, in unserem Interview. Das autonom fahrende Flurförderzeug interagiert mit dem Bediener wie ein Teamkollege und passt sich dessen Arbeitsrhythmus an. Weil es ihm dabei stets den Vortritt lässt, kann der Bediener frei um das Gerät herum agieren. Feldtests haben gezeigt, dass der autonome Helfer eine Zeitersparnis von bis zu 30 \% gegenüber herkömmlichen Fahrzeugen bei deutlich höherer Pickleistung ermöglicht, da das zeitaufwendige Auf- und Absteigen vom Fahrzeug deutlich reduziert wird. Möglich wird dieses interaktive Zusammenspiel von Mensch und Maschine durch zwei lasergestützte Motion-Tracking-Systeme, deren $60^{\circ}$-Sichtfeld das Fahrzeug in die Lage versetzen, permanent auf seine Umgebung zu reagieren. Diese sorgen dafür, dass das Kommissionierfahrzeug die Absichten des
Bedieners anhand seiner Bewegungen erkennt und mit diesem interagieren kann. Der Kommissionierer überzeugte auch die Jury des Logimat-Preises „Bestes Produkt“: Er gewann in der Kategorie Kommissionier-, Förder-, Hebe-, Lagertechnik. Was mich besonders bei der Vorführung des Fahrzeugs für die Presse am Vorabend der LogiMat beeindruckte, war die Entlastung des Fahrers, der sich nun auf seine Hauptaufgabe, das Kommissionieren, konzentrieren kann und dabei auch noch körperlich unterstützt wird.

Bekanntlich ist nach der Messe vor der Messe, so auch für die Flurförderzeughersteller. Ende Mai steht schon die nächste wichtige Messe im Terminkalender: die CeMAT 2016 in Hannover. Ich bin mir sicher, dass auch dort wieder zahlreiche Innovationen rund um Industrie 4.0 präsentiert werden.

Ich hoffe, wir sehen uns in Hannover.

Ihr

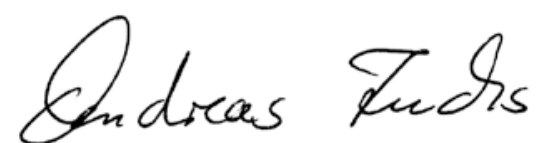

Andreas Fuchs

Chefkorrespondent

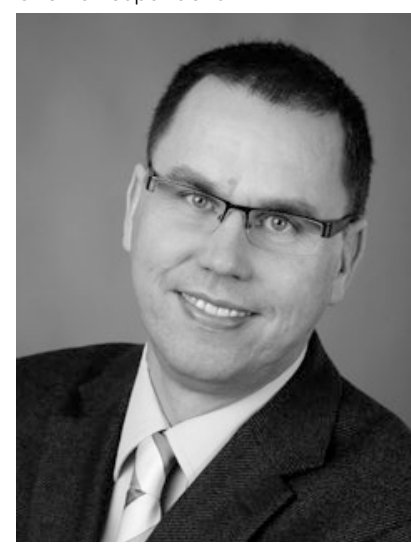

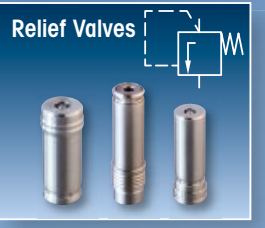

Flow Controls mum

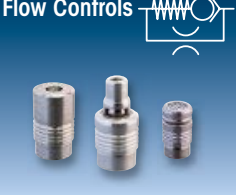

Restrictor Checks $\stackrel{\smile}{\smile O}$
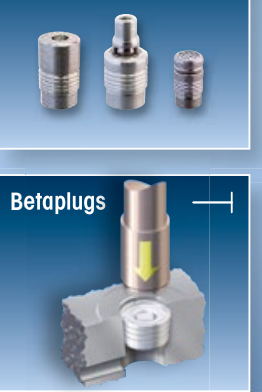

Calibrated Orifices $\longleftarrow$
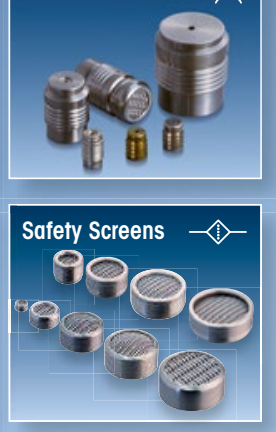

Shuttle Valves $\left.\prec \mathrm{O}_{T}\right\rangle$

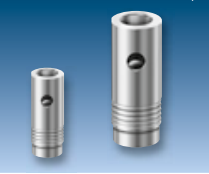

Airbleed

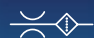
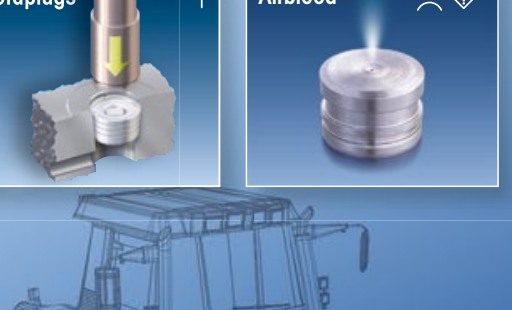

Innovation in Miniature

$®$ 